\title{
Infecção por HTL VI/II e doenças do tecido conjuntivo
}

\author{
Mônica Martinelli Nunes de Carvalho, Silvana Pereira Giozza, André Luiz Muniz Alves dos Santos, \\ Edgar Marcelino de Carvalho, Maria Ilma Araújo.
}

Em nosso estudo, avaliamos 137 indivíduos infectados pelo HTLV-1, dos quais apenas $5(3,6 \%)$ apresentaram anticorpos contra HTLV-2. A população desse estudo foi formada por portadores de HTLV-I, atendidos no ambulatório de HTLV, vinculado ao Serviço de Imunologia do Hospital das Clínicas, oriundos do Serviço de Transfusão Sangüínea e Hemocentro da Bahia ou ainda referenciados do Serviço de Neurologia do Hospital das Clínicas. Para o diagnóstico de mielopatia associada ao HTL V-I, os pacientes foram avaliados por dois neurologistas, que utilizaram os critérios da OMS. A Escala de Incapacidade Expandida de Kurtzke (EDSS) foi utilizada para confirmar que a limitação motora do paciente era causada por uma alteração neurológica, portanto, foram considerados portadores de mielopatia os indivíduos com EDSS maior ou igual a três, com função piramidal alterada maior ou igual a dois e liquor com sorologia positiva para HTL V-I. Desse modo, o fato de nossos pacientes serem em parte referenciados por ambulatório especializado e posteriormente submetidos à avaliação neurológica criteriosa justifica uma maior freqüência de mielopatia em comparação com o estudo mencionado.

A artrite reumatóide (AR) foi uma das doenças reumáticas auto-imunes mais freqüentes em nosso estudo; e sua maior prevalência em pacientes com mielopatia reforça a idéia de que mediadores inflamatórios, que levam ao aparecimento da mielopatia, também contribuem para o desenvolvimento da AR. Entretanto, a despeito das manifestações clínicas da artrite reumatóide clássica serem diferentes daquelas apresentadas pelos pacientes com artropatia associada ao HTLV-1, não se pode descartar a possibilidade de se tratar da mesma patologia.

Em um estudo em andamento, avaliamos 100 pacientes portadores de artrite reumatóide, e a freqüência de infecção pelo HTLV-I nessa população foi de $2 \%$. Um único caso de LES foi identificado em nosso estudo. A baixa freqüência do lúpus nos indivíduos infectados pelo HTLV-I pode ser justificada por ser o vírus indutor de resposta do tipo Thl, e esta pode se opor à produção de auto-anticorpos e, por conseguinte, prevenir o aparecimento do lúpus ou diminuir a gravidade da doença. Portanto, não foi possível estabelecer associação entre infecção pelo HTLV-I e LES.

Todos os resultados, no entanto, apontam para o possível envolvimento do HTLV-I na indução de doenças reumáticas auto-imunes e reforçam a necessidade de novos estudos metodologicamente mais adequados para a confirmação dessa hipótese. 